\author{
JOSÉ MARÍA SÁNCHEZ \\ UNIVERSIDAD DE SEVILLA
}

\title{
Los obradores artísticos sevillanos del siglo XV: adaptaciones y cambios para satisfacer los encargos del mercado americano
}

U na de las notas que caracterizó el mercado artístico sevillano durante el siglo Xvi fue el espectacular aumento producido en la demanda, consecuencia directa de los pedidos realizados desde los territorios americanos o de encargos peninsulares provenientes de los generosos caudales llegados de ultramar a instituciones civiles o religiosas y a determinados particulares.

Cuando a principios del siglo Xvi los mercaderes andaluces asumieron el reto del tráfico mercantil con las Indias, difícilmente podían imaginar la magnitud que éste alcanzaría. La creciente incorporación de territorios, con el avance del siglo, no hizo sino aumentar el volumen del comercio colonial, lo cual llevó a Sevilla a la etapa más floreciente de su historia económica. Como centro de exportación e importación de mercancías, la capital hispalense, cuya producción metropolitana pronto resultó insuficiente, se convirtió en la ciudad más próspera de Europa occidental.

Ciertamente la consolidación de la sociedad colonial generó un aumento paulatino de los encargos de productos peninsulares, sobre todo aquellos de difícil obtención en los nuevos territorios de ultramar, entre los cuales debemos situar las obras de arte.

En los embarcaderos del Guadalquivir se cargaron anualmente en cada flota miles de objetos "artísticos", número, sin duda, muy superior a lo hasta 
entonces demandado por el mercado local o comarcal. Ya no se trataba del encargo puntual de una obra para un acaudalado mecenas o un ciclo compuesto de varias piezas para una determinada institución, sino de decenas, centenas o incluso millares de obras solicitadas por los mercaderes de Indias para su envío a América.

Prácticamente, a lo largo del siglo Xvi Sevilla abastecerá a todo un nuevo mercado de escala continental.

Pero ese espectacular aumento de la demanda también se vio favorecido por la multiplicación de encargos patrocinados por individuos e instituciones peninsulares ahora beneficiados por las pródigas riadas de dinero procedentes de América. Numerosos conventos, parroquias, ermitas, cofradías y hermandades de toda Andalucía occidental fueron auxiliados por generosos donativos de indianos ricos que, sobre todo por medio de la fundación de capellanías, propiciaron el encargo de importantes ajuares litúrgicos, tales como retablos, pinturas y objetos de orfebrería, entre otros. Igualmente, en el ámbito civil, cabildos municipales, miembros de la nobleza, comerciantes asentados en el triángulo formado por Sevilla, el puerto de Santamaría y Cádiz, familiares de emigrantes y otros, aunque en menor cuantía, recibieron respetables sumas de dinero que, en parte, invirtieron también en la compra de obras de arte para el exorno de sus mansiones y palacios.

Así pues, por una vía u otra, los pedidos de obras de arte a los maestros sevillanos crecieron constantemente y de manera progresiva a lo largo del siglo XVI; esta situación provocó la necesidad de reconvertir los talleres y cambiar sus sistemas de producción, aspectos que pasamos a estudiar a continuación.

\section{Adaptación de los obradores}

Los artistas sevillanos o establecidos en el radio de acción de la ciudad tuvieron que adaptar sus talleres al nuevo mercado, efectuando notables cambios en sus pautas productivas y de organización del trabajo.

El tradicional obrador de pintura o escultura de carácter básicamente familiar, regentado por un maestro junto a alguno que otro aprendiz, se verá suplantado ahora por grandes talleres con un alto número de oficiales y aprendices para poder producir a gran escala. Tal es el caso de la conocida "Casa de los Ortega", obrador de imaginería fundado por el entallador Francisco de Ortega, donde durante la primera mitad del siglo Xvi trabajaron junto al 
maestro sus cuatro hijos: Nufro, Bernardino, Francisco y Bartolomé; ${ }^{1}$ o el caso del pintor Miguel Güelles, quien a principios del siglo XVII contaba en su obrador con seis aprendices: curiosamente este maestro dedicó casi toda su producción al mercado americano. ${ }^{2}$

Dentro de estos macrotalleres encontraron acomodo muchos maestros que prefirieron quedarse trabajando en ellos como oficiales a sueldo en lugar de abrir uno propio con los consiguientes gastos de instalación. En ese sentido, hay que señalar el caso del pintor Diego Rodríguez, quien en I529 entró al servicio conjunto de Cristóbal de Cárdenas y Andrés Martín para trabajar "en las obras que los susodichos tuvieren"; 3 o el del ollero Bartolomé de Castro, quien en I 560 se obligó a servir como oficial con Blas Cordero en el "arte de lo áspero", renunciando a la instalación de un obrador propio. ${ }^{4}$

Algunos maestros, para poder atender el nuevo volumen de los encargos, se asociaron para producir conjuntamente, conformando compańías mercantiles en las cuales, a veces, solía integrarse algún mercader para actuar como socio capitalista.

Por lo general, todas las compañías respondían a un esquema constitutivo similar y sus presupuestos legales se redactaban en los mismos términos, lo cual no quita para que, en cada caso, aparecieran determinadas particularidades. 5

Respecto a las cláusulas que solían fijarse al crearlas, los tres principios invariables eran: ejecución conjunta de las obras que se contratasen a partir

I. Jesús Palomero Páramo, El retablo sevillano del Renacimiento: análisis y evolución (I5601629) (Sevilla: Excma. Diputación Provincial, 1983), I22.

2. De este último se sabe que tenía un sobrino pintor, Leonisio Pinedo, establecido en el virreinato de la Nueva España, al que remitía para su venta cajones de pinturas, como el enviado en I619 con "treinta lienzos de ermitaños y ermitañas" (Celestino López Martínez, Arquitectos, escultores y pintores vecinos de Sevilla [Sevilla: Imp. Rodríguez Giménez, 1928], 57-58).

3. Antonio Muro Orejón, "Pintores y doradores", en Documentos para la Historia del Arte en Andalucía, vol. VIII (Sevilla: Universidad de Sevilla-Laboratorio de Arte, I935), 5 I.

4. Curiosamente por estos años la flota de Indias demandaba cientos de miles de botijas de barro para transportar aceite y vino a América, lo cual exigió de los alfares sevillanos unas pautas de trabajo que podríamos considerar de carácter preindustrial (José María Sánchez, El oficio de ollero en Sevilla en el siglo XVI, Colección Arte Hispalense, 65 [Sevilla: Excma. Diputación de Sevilla, 1994]).

5. El primer avance del estudio de las compañías artísticas lo encontramos en Juan Miguel Serrera, "Vasco Pereira, un pintor portugués en la Sevilla del último tercio del siglo Xvi", Archivo Hispalense LXX, núm. 213 (Sevilla: Excma. Diputación Provincial, 1987): 197-237. 
de su constitución; propiedad única de las obras, y comunidad de gastos y reparto de beneficios a partes iguales, incluso si alguno de los maestro caía enfermo y no podía trabajar en los citados encargos. ${ }^{6}$

Cuando las compañías se constituían entre miembros de una misma familia — por lo general entre suegro y yerno—, también se solía estipular que correrían a partes iguales los gastos de sustento de ambas ramas, llevándose buena cuenta de todo ello en un libro en el cual se asentaban los pagos.

Dentro del mundo de las compañías sevillanas del siglo Xvi podemos citar la formalizada por el entallador Juan de Giralte y su suegro el pintor Juan de Zamora en torno a 1564, que les permitió satisfacer los numerosos encargos para las iglesias y los monasterios de la diócesis de Sevilla, ahora también beneficiados de las riadas de oro y plata americanas; ${ }^{7}$ o la establecida en 1570 entre los pintores Juan de Salcedo y Juan de Tejada, cuyo plazo de vigencia se estipuló en ro años y que, desde el momento de su constitución, se apropió de todas las obras ya comenzadas, salvo aquellas cuyo montante no alcanzaba los 50 ducados. ${ }^{8}$

Otro caso muy significativo fue el del pintor portugués Vasco Pereira, quien formó parte de tres: la primera la creó en unión de Alonso Vázquez para pintar la iglesia renovada del monasterio de Santa Paula de Sevilla, relación propiciada ante la imposibilidad de dar cumplimiento al encargo debido a su enorme envergadura; 9 respecto a las otras dos, las constituyó con el pintor ga-

6. El pintor Francisco Martínez, en su testamento redactado en Sevilla el 5 de febrero de I555, declaró que había formado compañía con Alonso Hernández y que ambos contrataron las pinturas de la casa de un tal Rodrigálvez, vecino del barrio de la Carretería, y, aunque la ejecución corrió a cargo solamente de Hernández por encontrarse enfermo Francisco Martínez, éste cobró el importe que le correspondía como estaba establecido por las cláusulas de la citada compañía (Celestino López Martínez, Desde Jerónimo Hernández hasta Martínez Montañés [Sevilla: Imp. Rodríguez Giménez, 1929], 198, y José Gestoso, Ensayo de un diccionario de los artífices que florecieron en Sevilla desde el siglo XIII al XVIII inclusive, vol. II [Sevilla: Andalucía Moderna, I900], 355).

7. Palomero Páramo, El retablo sevillano, 160.

8. López Martínez, Arquitectos, escultores y pintores vecinos de Sevilla, 198.

9. El contrato incluía las 36 tablas del retablo mayor y los dos laterales, las seis de la viga del presbiterio, las cuatro de las puertas del comulgatorio, las Virtudes de las puertas de la sacristía, I5 filacterias de madera, siete escudos grandes, los escudos de la techumbre y las pinturas murales que decorarían las tumbas de los fundadores del monasterio, la bóveda y los muros de la capilla mayor, el arco toral y el friso circundante de la nave de la iglesia (Celestino López Martínez, Desde Martínez Montañés hasta Pedro Roldán [Sevilla: Imp. Rodríguez Giménez, 1932], 209-213). 
ditano Pedro Román y con el sevillano Antón Pérez, maridos respectivamente de sus dos hijas, en ambos casos para poder atender fundamentalmente los numerosos encargos de policromía que por entonces le habían solicitado. ${ }^{\text {Io }}$

En ocasiones, a la muerte de un artista, su viuda podía crear una compañía con otro maestro del mismo gremio para mantener abierto el taller y finalizar las obras que habían quedado inconclusas por el fallecimiento de su marido. Tal es el caso de Luisa Ordóñez, viuda de Gerónimo Hernández, quien en 1586 estableció con su cuñado Andrés de Ocampo una compañía "de escultura, talla y ensamblaje”. Ésta quedó constituida por tiempo indefinido "desde hoy hasta que el primero de nos fallezca" y convenía que Ocampo recibiría "la mitad de todas las obras que mi marido dejó comenzadas [...] para que las hagáis y acabéis y, por ello, habéis de llevar la mitad de los maravedíes que por cada una de ellas se han de dar", mientras que Luisa Ordóńez se haría cargo de la otra mitad contratando oficiales para trabajar por ella. También se concretó que

todas las obras que de hoy día en adelante hasta que fallezca cualquiera de nos adquiriéremos y nos fueren encargadas, así por diligencia de mí Luisa Ordónez como por razón de las muestras que dejó Gerónimo Hernández, mi marido, y que yo Andrés de Ocampo asimismo adquiriere en cualquier manera, se han de partir de por medio, haciendo yo Luisa Ordóńez con mis oficiales la mitad de cada una e yo Andrés de Ocampo la otra mitad; y cada uno de nos a de llevar la mitad de los maravedíes que por las dichas obras se dieren. ${ }^{\text {II }}$

En relación con el mundo americano, conocemos también la existencia de compañías formadas por artistas y mercaderes, donde estos últimos actuaban como socios capitalistas, es decir, adelantando el dinero para la compra de los materiales necesarios para producir las obras. Posteriormente, se comercializarían en ultramar obteniendo cada parte los beneficios pactados. Un ejemplo es la constituida por el pintor Pedro de Campaña, "el Joven”, y un sastre que, en el momento de su disolución, el i8 de mayo de I59I, contaba en su haber con 12 imágenes de la Virgen de la Antigua, pintadas por el primero y costeadas por el segundo. Antes de proceder a su venta se tasaron, acordándose que cada uno recibiría la mitad. ${ }^{\mathrm{I}}$

\footnotetext{
Io. Serrera, "Vasco Pereira, un pintor portugués", 22 I-223.

I I. Palomero Páramo, El retablo sevillano, 275-277.

I2. López Martínez, Desde Martínez Montañés hasta Pedro Roldán, 24 y I73.
} 
Otro caso parecido ocurrió con la compañía formada por el escultor Desiderio Balleoso y el mercader y lapidario Juan del Fuergo; esta asociación se disolvió, a los tres meses de constituirse y ambos solicitaron la tasación de las mercaderías que por entonces constituían el patrimonio común. ${ }^{\mathrm{I3}}$

Esta clase de concierto la formalizaron todo tipo de artistas, tanto pintores como bordadores, escultores u olleros. ${ }^{\text {I4 }}$

Ante tal panorama cabría preguntarse si dentro del mundo de las compañías artísticas sevillanas del siglo XVI realmente se dieron individualidades o, por el contrario, habría que hablar de obras colectivas, ejecutadas con una técnica y un sistema casi artesanal. Ciertamente, en los obradores donde estaban vigentes tales compañías podrían plantearse serios problemas de atribución de las obras por razones estilísticas a uno u otro maestro. Quizá sólo podrían considerarse simple y llanamente obras de las respectivas compañías, con independencia de si intervinieron por igual o no los maestros que en cada caso las conformaban.

De cualquier manera, debemos señalar que en el siglo Xvi el artista sevillano todavía seguía siendo un artesano, el jefe de un taller en el cual se trabajaba en equipo. Al respecto, conviene precisar que ese sistema de trabajo no se correspondía con el clásico concepto de la creación artística imperante en los talleres italianos del Renacimiento, donde la concepción de la idea estaba separada de su ejecución. Aquí el asunto era bien diferente, pues, por lo general la "idea" de la que partían las obras, en especial las ejecutadas en los talleres dedicados a la producción americana, estaba tomada casi siempre de estampas. ${ }^{\text {I5 }}$

\section{Cambios en los sistemas de producción}

El aumento de la demanda de obras de arte en la Sevilla del siglo Xvi no afectó solamente a la estructura organizativa de los obradores sino que también condicionó los modos de producción, siempre matizados por la naturaleza de los encargos.

13. López Martínez, Desde Martínez Montañés hasta Pedro Roldán, 24.

I4. Para comprobar los contratos de compañía celebrados por los bordadores sevillanos, cf. Isabel Turmo, Bordadores y bordados sevillanos (siglos XVI a XVIII) (Sevilla: Universidad de Sevilla-Servicio de Publicaciones, 1955), 96, 98 y 99.

15. Véase particularmente De Amberes al Cusco: el grabado europeo como fuente del arte virreinal, eds. Cécile Michaud y José Torres Della Pina (Lima: Pontificia Universidad Católica del Perú-Centro Cultural, 2009). 
A lo largo del siglo XVI convivieron en los obradores sevillanos dos sistemas de producción: uno, muy minucioso y de gran calidad técnica, destinado a satisfacer encargos puntuales, tanto en el ámbito local como de ultramar, realizados a instancias de acaudalados comitentes o de importantes instituciones de carácter civil o religioso; otro, más mediocre, con ciertas notas de seriación, con destino preferente al mercado colonial y cuyo objetivo era cubrir los pedidos — siempre muy cuantiosos — realizados por los mercaderes americanos.

Conviene destacar que ambas fórmulas de producción convivieron en los mismos talleres y fueron practicadas por los mismos maestros; por ello, el tema de los artífices no es, de por sí, el elemento clave para diferenciarlas. De hecho, dependiendo del tipo de demanda, un mismo maestro podía aplicarse a uno u otro método de producción.

Esa dualidad de sistemas la pusieron en práctica la mayoría de los artistas que trabajaron para el mercado americano, entre otros los pintores Villegas Marmolejo, Diego de Sarabia y Francisco Pacheco o los escultores Juan Bautista Vázquez el Viejo y Martínez Montañés.

La producción de obras seriadas a instancias de los mercaderes fue la que detentó, cuantitativamente, el papel más importante. Podemos señalar la presencia de cientos o incluso miles de obras de arte que, a instancias de los mercaderes, se registraron anualmente en las flotas con destino a América.

La producción de este tipo de obras estuvo condicionada por tres factores: en primer lugar, por la relación entre el gran volumen de los pedidos y el corto plazo dado para su ejecución, el existente entre las fechas de partida de las flotas - había que producir mucho en poco tiempo-; en segundo lugar, por los bajos precios pagados por estas obras, pues a la cantidad inicial fijada por el maestro que las ejecutaba se sumaban los gastos de la travesía y el margen de riesgo-beneficio del propio mercader, y en tercer lugar, por el bajo nivel de exigencia de calidad requerido por la clientela a la cual estaban destinadas. ${ }^{16}$

De la conjunción de estos tres condicionantes resultó, como no podía ser de otra manera, una producción, en líneas generales, bastante mediocre.

Un ejemplo muy esclarecedor de tal situación lo constituye el encargo que el 26 de junio de 1600 realizó el mercader toledano, por entonces estante

16. De hecho, en relación con las pinturas religiosas, las cuales se embarcaron mayoritariamente en el siglo XVI con destino a América, no preocupaba especialmente la calidad de la obra, ni siquiera el artista que las realizaba, sino simplemente su carácter de "devotas". 
en Sevilla, Gonzalo de la Palma Hurtado, al pintor Miguel Vázquez de "mil retratos de figuras profanas", todos de una misma medida, aproximadamente $62 \times 4 \mathrm{I} \mathrm{cm}$, que habría de entregar en Io meses y cuyo precio se estipuló en 4 reales. ${ }^{17}$ El volumen del pedido fue, sin duda, muy elevado en contraste con el escaso tiempo destinado para su ejecución — debía entregarlos en lotes de 25 cada semana lo que, admitiendo incluso que trabajara el domingo, suponía pintar tres retratos y medio cada día-, lo cual, unido al bajo precio de tasación, implicaría necesariamente una ejecución no muy cuidada.

Normalmente, las pinturas se reseñaron en los registros de mercancías de las naves con el calificativo de "comunes u ordinarias", como queda constancia en el envío que en I597 realizaron Diego López de Herrera y Alonso de Herrera Torres en la nao San Buenaventura con destino a Nueva España: "cincuenta y cinco lienzos comunes pintados a 8 reales, I 4.960 maravedíes; trece lienzos comunes medianos a I5 reales, I.768 maravedíes". ${ }^{8}$

Para producir con rapidez y al más bajo costo fue frecuente encargar obras de una misma temática y en un mismo formato. ${ }^{19}$ Repitiendo la iconografía a un tamańo idéntico se agilizaba, sin duda, el proceso de ejecución, aunque el resultado fuera inevitablemente una obra de carácter seriado.

Además, en los envíos donde quedó concretada la iconografía se advierte cómo las obras solían representar una sola figura, aspecto éste que también contribuiría a simplificar la ejecución. Sirva de ejemplo un protocolo de 1584 donde el mercader Antonio de Aranda declaró que debía a Juan de Chacón, pintor de imaginería, 24 ducados por razón de "seis ecce-homo de medio relieve de bulto que me habéis vendido"2o o el registro de Martín de Berganzo Gamboa de 7 de septiembre de 1598 en el cual, entre otras muchas mercaderías, figuraba un cajón con "I03 lienzos de figuras de devoción de medios cuerpos de Santos", tipología que responde claramente a la de las pinturas concebidas como mercaderías. ${ }^{21}$

Otra nota que caracterizó este tipo de producción fue su bajo precio, siempre muy inferior al de las obras no destinadas a los mercaderes y, por tanto, no

17. López Martínez, Desde Martínez Montañés hasta Pedro Roldán, 218, en Serrera, "Vasco Pereira, un pintor portugués", 225.

I8. Archivo General de Indias (en adelante AGI), Contratación, I I23, año I597, I3 I r/v.

19. Respecto al tamańo, no las define como grandes o pequeñas, sino que todas tuvieran las mismas medidas.

20. López Martínez, Desde Martínez Montañés hasta Pedro Roldán, I78.

2I. AGI, Contratación, II30, año I598, I34 r-I38v. 
ejecutadas en serie. Las pinturas, por ejemplo, se cotizaron entre 5 y I 2 reales, cuantías no muy superiores a las de las estampas que se registraban en esos mismos envíos, en su mayoría procedentes de otros mercados. ${ }^{22}$

Los precios, al parecer, pudieron estar en relación con el tamaño de las obras, si bien esa relación no puede establecerse como norma, ya que intervenían otros factores, en especial, la temática como elemento corrector y el número de obras por encargo. De hecho, a mayor número de cuadros de un mismo formato que repetían una misma composición, menor sería el costo. Así se pone de manifiesto en el concierto que el pintor Pedro Calderón firmó en 1596 con el corredor de lonja Juan Esteban de Giles. Los "cincuenta retratos de historias y figuras profanas" del encargo tendrían todos el mismo "tamaño y forma" que uno presentado como "muestra". Como todos tendrían el mismo formato y responderían a los mismos esquemas compositivos, se comprende que se comprometiera a pintarlos en dos meses y que, por contra, el corredor de lonja sólo le pagara 24 reales por cada uno. ${ }^{23}$

Este sistema repercutió también en la autoría, pues posiblemente en la realización de las obras apenas intervenía el maestro, ejecutándolas sus oficiales junto a los más habilidosos aprendices, considerándosele así obras de taller. Sin duda, el maestro sólo actuaría en la fase final para perfilar algún detalle o practicar ciertos retoques. En el anterior ejemplo del encargo a Miguel Vázquez de "mil retratos de figuras profanas", sabemos que parte de la ejecución correspondió al pintor Sebastián de Antonio Romana, quien firmó con Vázquez un contrato por medio del cual se obligaba a pintar en su taller por 4 reales al día, cantidad curiosamente coincidente con los que su patrón recibiría por cada retrato. ${ }^{24}$

22. En I 596 el licenciado Francisco López Maruel, médico físico vecino de Sevilla, registró en las bodegas del navío El Espíritu Santo, con destino a tierra firme, una caja de su uso con distintos objetos entre los que figuraban "una estampa de un San Cristóbal de a tercia y más luminada en 8 reales" y otra "de una Santa Marina puesta en tabla en 6 reales" (AGI, Contratación, III4, año I596, núm. I, 63r-65r). Además, conocemos documentalmente que pinturas y estampas compartieron protagonismo en los registros de mercancías con destino a América: hacia 1595 Vasco Pereira, conjuntamente con su yerno Pedro Román, remitió a Tierra Firme un cajón "con estampas y lienzos de pintura”, actuando como intermediario el capitán Juan de Soto, quien cobró 500 reales de plata por la parte del beneficio que le correspondía (López Martínez, Desde Jerónimo Hernández hasta Martínez Montañés, I89).

23. López Martínez, Desde Martinez Montañés hasta Pedro Roldán, en Serrera, "Vasco Pereira, un pintor portugués", 226.

24. López Martínez, Desde Martínez Montañés hasta Pedro Roldán, 2 I8. 
La presencia de estos oficiales y aprendices aplicados a este tipo de producción seriada permitió, en ocasiones, la continuidad del obrador tras el fallecimiento del maestro, regentado por la viuda. ${ }^{25}$

En ese sentido, otro rasgo de las obras de arte ejecutadas para los mercaderes es que casi nunca aparecen firmadas ni fechadas, pues ni al comitente ni a los futuros compradores asentados al otro lado del Atlántico les preocupaban tales detalles. La omisión de estos datos acentúa la naturaleza mercantil de esta producción artística.

Por todo ello, muchas obras destinadas al mercado colonial podrían considerarse simples mercaderías, pero no por el hecho de ser ejecutadas por malos artistas, los por entonces llamados "pintamonas", sino por el sistema adoptado para su ejecución, marcado, sobre todo, por el corto plazo de tiempo dedicado a cada una y por la amplia participación del taller.

En la Sevilla del siglo Xvi abundaron los malos pintores, de quienes se tienen testimonios por medio del teatro de la época, ${ }^{26} \mathrm{y}$, aunque en lo relativo a la calidad sus lienzos podrían equipararse a los de los maestros dedicados al comercio, se diferenciaban de ellos en cuanto al proceso ejecutivo y en lo referente a los niveles de producción, pues por muy amplia que fuera su obra nunca alcanzaría los niveles casi industriales de los otros pintores.

No debemos descartar, no obstante, que una parte de la producción de los maestros dedicados al comercio de pinturas acabara vendiéndose en las calles de Sevilla, bien a través de ellos mismos en mercadillos especializados o por medio de pintores ambulantes. ${ }^{27}$

Todas estas prácticas continuaron vigentes a lo largo del siglo XVII, etapa en la que incluso se incrementó la producción seriada de obras de arte destina-

25. Un testimonio tardío es el caso de la viuda del pintor Juan de Luzón quien, aun tras la muerte de su marido, entregó al capitán Pedro Moreno "un cajón de pintura en que iban I 8 lienzos de a dos varas y de dos varas y cuarto cada uno" para que lo llevase a tierra firme y vendiera los lienzos por su cuenta (Duncan Kinkead, "Juan de Luzón and the Sevillian Paintings Trade with the New World in the Second Half of the Seventeenth Century", Art Bulletin 66, núm. 2 [New York College Art Association of America, I984]: 303-3 I0, doc. 6).

26. Como un tal Orbaneja, citado por Cervantes en el Quijote (Javier Portús Pérez, "Un cuentecillo del Siglo de Oro sobre la mala pintura: Orbaneja”, Boletín de la Institución Libre de Enseñanza II, núm. 5 [Madrid, I988]: I85-210).

27. Francisco Manuel Martín Morales, "Aproximación al estudio del mercado de cuadros en la Sevilla barroca I600-I670", Archivo Hispalense LXIX, núm. 2 Io (Sevilla: Excma. Diputación Provincial, I986): I54-160. 
das al comercio tanto indiano como peninsular. Conocidos documentalmente son los envíos de los pintores Miguel Güelles, Juan de Fajardo, Juan López de Carrasco y Juan de Luzón, pero en especial ha sido estudiada la actividad comercial de Francisco de Zurbarán con América. ${ }^{28}$

En el caso de Zurbarán, se comprueban documentalmente remesas de pinturas consignadas por el maestro al virreinato del Perú, en particular a la ciudad de Lima, las cuales repiten las notas que hemos analizado para gran parte del comercio artístico del siglo xvi. Por lo general, consistieron en cuantiosas partidas de lienzos casi siempre agrupados en series iconográficas — sibilas, vírgenes mártires, ángeles, apóstoles, eremitas, reyes y personajes “ilustres”-, pues repitiendo un mismo tema con un formato similar se facilitaba su realización y se abarataban los costos; igualmente sabemos que en su factura tuvieron una importante participación los oficiales y aprendices de su $\operatorname{taller}^{29}$ y, quizá por ello, en las partidas de registro de las naves donde quedaron anotados no consta el nombre del maestro ni los lienzos conservados contienen su firma, aspecto éste que, por otra parte, no importaba especialmente a la clientela a la cual iban destinados. ${ }^{30}$

El resultado final de estas prácticas, como cabría esperar, fueron unas obras de escasa calidad y con tintes de seriación, al menos desde la óptica actual, que, sin embargo, cumplían holgadamente con sus propósitos, al servir

28. Véase Juan Miguel Serrera, "Zurbarán y América”, en Zurbarán (Madrid: Ministerio de Cultura, 1988), 63-83; Jesús Miguel Palomero Páramo, "Notas sobre el taller de Zurbarán. Un envío de lienzos a Portobelo y Lima en el año I636", en Extremadura en la Evangelización del Nuevo Mundo: Actas y Estudios, congreso celebrado en Guadalupe durante los días 24 al 29 de octubre de 1988 (Madrid: Turner, 1990), 313-330, y Benito Navarrete Prieto, Zurbarán y su obrador. Pinturas para el Nuevo Mundo (Madrid: Ayuntamiento de Madrid, 1998).

29. Así quedó testimoniado en un pleito formado en I640 en torno a ciertas pinturas que el artista entregó al capitán Diego de Mirafuentes para su venta en la feria de Portobelo donde José Durán, discípulo del maestro, en calidad de testigo declaró que "la mayor parte de ellas eran originales, hechas en casa del dicho Francisco de Zurbarán por su mano y de otros oficiales del arte de la pintura de los mejores de esta ciudad" (Palomero Páramo, "Notas sobre el taller de Zurbarán").

30. Así lo señalan Julián Gállego y José Gudiol al comentar: "los talleres sevillanos de la época de Zurbarán eran auténticas fábricas de cuadros al por mayor” (Julián Gállego y José Gudiol, Zurbarán. I598-I664 [Barcelona: Polígrafa, I976], 39) y María Luisa Caturla, al referirse a las obras enviadas por Zurbarán al Nuevo Mundo: "el maestro no ponía en ellos apenas el pincel” (María Luisa Caturla, "Francisco de Zurbarán”, en Catálogo Zurbarán [Madrid: Dirección General de Bellas Artes, I953], 4I). 
a prácticas devocionales privadas o contribuir al prestigio y crédito social de sus propietarios. ${ }^{31}$

No obstante, como anticipábamos líneas arriba, junto al sistema de producción seriado, en los talleres sevillanos convivió otro de elaboración más cuidadoso y minucioso, destinado a cubrir los encargos realizados a instancia de acaudalados mecenas o de importantes instituciones de carácter civil o eclesiástico tanto espańolas como coloniales.

Cuando los pedidos llegaban de ultramar, se realizaban generalmente por medio de comisionados establecidos en Sevilla, vinculados con el comitente por lazos profesionales o de amistad, que entraban en contacto con los talleres locales transmitiéndoles los deseos del cliente.

Sin embargo, también encontramos "pasajeros" que se embarcaban en las flotas con destino a Sevilla para realizar el encargo y permanecían en la ciudad hasta su finalización. Tal es el caso de Hernando del Río, natural y vecino de la "Isla Española", que el 6 de noviembre de 1545, desde el puerto de Sevilla, remitía a la ciudad de Santo Domingo un retablo embalado en io cajas para ponerlo en su iglesia catedral, costeado por el tesorero Diego del Río, "de su propio dinero y a su riesgo",32 o de Juan Gómez y Diego Núnez, quienes en 1598 fueron comisionados por Francisco Terrín, alguacil mayor y depositario general de la ciudad de Panamá, para que contrataran en su nombre, en la capital hispalense, un retablo destinado al presbiterio del convento de la Limpia Concepción fundado por él en aquella ciudad. ${ }^{33}$

En ambos casos, esta fórmula permitía un control exhaustivo del proceso de producción de la obra, especialmente por medio del sistema de pago a plazos.

3I. En relación con el virreinato del Perú puede consultarse el reciente estudio de Suzanne Stratton-Pruitt, "From Spain to the Viceroyalty of Peru. Paintings by the Dozen", en At the Crossroads: The Arts of Spanish America and Early Global Trade, I492-I850, eds. Donna Pierce y Ronald Otsuka, Symposium Series (Denver: Denver Art Museum/University of Oklahoma Press-Mayer Center for Pre-Columbian \& Spanish Colonial Art, 2012).

32. AGI, Contratación, I079, año I $545,684 \mathrm{r} / \mathrm{v}$.

33. Éstos otorgaron escritura de compromiso en la fecha indicada con Diego López Bueno y Juan Martínez Montañés, encargándose el primero de las labores arquitectónicas y el segundo, de las escultóricas. El precio convenido se fijó en 936 ducados. Las trazas se enviaron por el citado Terrín a sus comisionados, según se advertía en el protocolo del contrato: "de la manera que se contiene en la memoria que vino de Yndias". Posteriormente, el 4 de agosto de I599, ambos maestros subarrendaban su policromía, dorado y estofado a Gaspar de Ragis (Alfonso Pleguezuelo y José María Sánchez, "Diego López Bueno y su obra Americana”, Anales Museo de América, núm. 9 [200I]: 275-286). 
Las obras, una vez terminadas, se embalaban cuidadosamente y se remitían en la primera flota que partiera hacia el lugar de destino, corriendo los gastos y riesgos de la travesía a cargo del comitente. ${ }^{34}$

Normalmente, la rudeza del trayecto provocaba desperfectos en las obras, a pesar de empacarse con todo cuidado en rígidos cajones - las pinturas, a su vez, dentro de cañones o canutos de hojalata- y fuertemente entibadas con materiales elásticos como madejas de hilo y ropas; por ello, casi siempre era necesario repararlas en destino. Francisco Gómez de Marro, natural de Ciudad Rodrigo y residente "más tiempo de catorce años" en las provincias del Perú, a propósito de la falta de maestros de imaginería en aquellas tierras comentaba en I553:

en aquellas provincias no hay las dichas imágenes sino las que de España se llevan, las cuales son muy caras y hacen mucha costa y no pueden ser habidas y cuando allá van llegan muy maltratadas e quebradas y desfiguradas y habiendo los dichos maestros en aquellas partes será muy bueno porque estarán muy buenas y enteras y frescas y como conviene y las habrá en todos los templos y a más moderados precios. ${ }^{35}$

Formaron parte de este tipo de producción toda clase de imágenes y símbolos relacionados con la Casa Real española destinados a presidir cabildos, audiencias y tribunales americanos; grandes cantidades de imágenes religiosas para conformar los ajuares litúrgicos de iglesias, monasterios y oratorios privados, y otras obras de carácter suntuario dedicadas al ornato de los palacios y las grandes casas coloniales.

Finalmente, también conviene señalar que muchos artistas sevillanos del siglo XVI, por iniciativa propia, es decir, sin mediar encargo alguno, destinaron parte de su producción al mercado americano, atraídos por la posibilidad de obtener grandes beneficios con las ventas. Ciertamente, el precio de las obras se podía triplicar o quintuplicar en los puertos y las ciudades de ultramar en relación con su alta demanda por las nuevas elites de la sociedad colonial y, al mismo tiempo, por la escasez de estos bienes de lujo. ${ }^{36}$

34. El retablo anteriormente citado se envió a Panamá en I60I en la flota de Tierra Firme comandada por el general Francisco del Corral y Toledo.

35. AGI, Indiferente, 2079, núm. 7, año I 554.

36. En el citado pleito de Zurbarán con el capitán Diego de Mirafuentes, Diego Muñoz Naranjo declaró "que si los hubiera querido vender en esta ciudad (Sevilla) se los pagaban aventajadamente por ser muy buenos y que la causa de dárselos al dicho D. Diego de 
Muchos maestros orientaron la totalidad de su producción a este mercado; otros, en cambio, sólo remitieron obras en momentos puntuales, cuando escaseaban los encargos locales o su actividad decaía por las coyunturas — crisis económicas, aparición de nuevos maestros con propuestas más modernas, pérdida de calidad, entre otras.

Todas estas obras tuvieron en común un destino incierto, pues no iban a instancia de parte, lo que permitía al autor trabajar sin las exigencias o imposiciones de calidad marcadas por el comitente.

Para su comercialización, los artistas entraban frecuentemente en contacto con miembros de las tripulaciones de los navíos para que, llevándolas consigo, intentaran venderlas "a los mejores precios que pudieren haber o hallar", debiendo esperar el regreso de la flota para cobrar los beneficios.

Los maestres y capitanes fueron, casi siempre, las personas elegidas para estos tratos, pues en ellos se podía tener absoluta seguridad y confianza, quedando beneficiadas ambas partes: los remitentes al poderse sentir tranquilos y confiados en el cumplimiento de su voluntad y los citados maestres o capitanes al obtener algún beneficio económico ańadido a sus exiguos sueldos.

\section{La relación artista-cliente: el sistema contractual}

Los dos sistemas de producción que hemos estudiado tuvieron en común que la mayoría de los encargos se realizaron vía contrato, aunque variando sensiblemente las cláusulas y condiciones presentes en cada caso.

Inmersos en una cultura en la que el legalismo formal era una de sus características más acusadas, los artistas sevillanos y sus clientes fijaron por medio de escrituras públicas hasta los más mínimos detalles de su relación comercial, donde factores como lugar, tiempo y modo se determinaron desde el principio con absoluta precisión.

En los contratos de obras seriadas se advierte, por parte de los mercaderes, una total despreocupación por las cuestiones propiamente artísticas, reseñándose sólo con minuciosidad número, precio, tamaño y fecha de entrega de las obras, concretados con la frialdad propia del lenguaje comercial.

Mirafuentes fue porque le dijo que en las Indias le haría dar tresdoblados el dinero que aquí le daban por ello" (Palomero Páramo, "Notas sobre el taller", 323-324). 
A diferencia de lo que ocurría cuando se trataba de encargos de obras puntuales, en los conciertos de obras seriadas sus cláusulas no contenían: referencia a los materiales, tales como sistemas de armazón, tipo de telas, número de manos de la imprimación o calidad y procedencia de los colores; especificación alguna de que la ejecución debiera ser "de la mano" del artista que firmaba el contrato, sin prohibirle contratar otras obras mientras no la hubiera entregado; ni requisito de tasación a su finalización, pues además de que no inquietaba mucho al mercader el control de la calidad, de plantearlo le supondría un aumento en los costos: el pago a los maestros tasadores.

Como se advierte, a los mercaderes no les preocuparon excesivamente aspectos tales como la calidad de las obras o la idoneidad de los artistas con quienes contrataban, pues en última instancia sus encargos se hicieron siempre a quienes, sin plantearles especiales problemas creativos, se comprometían a entregar las obras en la forma y en el tiempo estipulados, siendo éste, de hecho, el requisito más importante.

En el caso de los encargos financiados por importantes comitentes y que requerían un tratamiento más particular, el funcionamiento de los contratos cambió sensiblemente.

En ellos sí se incluyeron cláusulas pormenorizadas en lo concerniente a las condiciones técnicas y en buena parte estilísticas de las obras. Se fijó con precisión todo lo referente al uso de los materiales, a la ejecución técnica, la ordenación temática e incluso a la composición general de la obra, junto a otras cláusulas relativas al precio y modo de pago y al plazo de ejecución, entre otras.

En estos encargos, por lo general, era el cliente quien elegía al artista. Sin embargo, en más ocasiones de las que parece, en especial en obras de cierta envergadura económica, se recurría a la fórmula del contrato de adjudicación a la baja. Cuando así ocurría, el cliente encargaba a un artista, casi siempre de prestigio, que redactase las condiciones técnicas y estableciese, de acuerdo con él, las cláusulas económicas del contrato. Fijado el día de la subasta por medio de un edicto, a ella podían acudir cuantos maestros quisiesen, adjudicándose la obra a quien, cumpliendo las condiciones reseñadas, se comprometiera a realizar la obra por el menor precio.

Para valorar en su justa medida este tipo de conciertos, analizaremos, a título de ejemplo, las cláusulas del contrato que se protocoló en 1565 para la ejecución del retablo mayor de la catedral de Chiapas, costeado a partir de un donativo real. Éste decía así: 
Primeramente, el maestro que esta obra tomare ha de hacer un retablo del modo que está trazado en una traza que para él está hecha y con los mismos compartimentos; y el retablo ha de ser hecho en lienzo de la manera siguiente:

- Primeramente, ha de ser obligado a su costa de poner el lienzo, el cual ha de ser de ruán de cofre, muy bueno y liso, sin motas y ha de cortar este lienzo por los compartimentos de manera que no haya costuras por medio de los retablos, sino que las juntas que hubiere sean por las juntas de la arquitectura y así vaya haciendo todos sus tableros de manera que después de hecho se arme como si fuese de madera.

- más, sea obligado de aparejar todos los dos lienzos con los aparejos que se requieren para pintarse a óleo y vayan muy bien correteados; encima de este aparejo le dé una mano de imprimadura a óleo muy bien molida, de manera que no se quiebre.

- más, trace en cada tablero su arquitectura conforme a como está en la traza, de manera que después sea toda como dicho es.

- más, sea obligado de pintar en cada un tablero las historias que en las trazas están señaladas y las pinte de esta manera: que bosqueje todas las historias al óleo muy bien dibujadas y abosquejadas conforme a buena obra; ítem, después de seco el abosquejado, lo pinte al óleo de sus colores, muy finos, dándole a cada cosa su luz, con sus claros y oscuros y sus lejos conforme a buena obra; ítem, más, sea obligado de barnizar toda esta pintura de manera que quede muy lustrante como por efecto es menester.

- más sea obligado el maestro que esta obra tomare de dorar toda su arquitectura y molduras de este retablo de oro mate, sacándole encima del oro y relavándole todas las columnas y molduras y frisos y remates, de manera que parezca ser de talla, y esto ha de ser obrado al óleo conforme a buena obra.

- ítem, ha de tener este retablo por la parte de en medio hasta el fin de él, Dios Padre, siete varas, e por los lados ha de tener seis varas de anchura, todo lo cual ha de hacer a su costa y lo ha de dar hecho dentro de dos meses y medio.

- y entiéndese que el aparejo con que se ha de aparejar sus lienzos para la pintura del dicho retablo, no ha de ser aparejo que salte la pintura sino el cual conviniere para que ella se haga muy buena y que dure. Lienzo de Salvatierra [entre renglones]

- ítem, es condición que acabada de hacer la dicha obra, si a el dicho señor factor le pareciere e quisiere, pueda poner oficiales pintores de imaginería para que vean si está acabada conforme a la buena obra y las dichas condi- 
ciones; e no estándolo pague de pena doce ducados para la cámara del fisco de su Majestad. Alonso de Salvatierra escribano. ${ }^{37}$

Tales cláusulas y condiciones de ejecución del retablo fueron redactadas por cierto maestro - que en ningún momento aparece nombrado- a instancias del juez de la Casa de la Contratación Francisco Duarte. Posteriormente, la obra salió a subasta pública, a la cual concurrieron tres importantes pintores sevillanos: Luis de Vargas, Pedro de Villegas Marmolejos y Luis Hernández, quienes realizaron distintas posturas, rematándose finalmente la obra a Luis Hernández, quien licitó el precio más conveniente.

Así pues, como queda patente en la documentación, un maestro fue el autor de la traza, concretada mediante un boceto, y otro, en este caso Luis Hernández, el que la ejecutó; en consecuencia, se debe considerar igualmente a ambos maestros como coautores del retablo.

De esa dualidad, de la presencia de un artista que concibe la obra y de otro que la realiza, siguiendo un boceto o modelo ajeno, da fe el concierto establecido en 1592 entre el pintor Pedro Bautista y Gaspar de Figueroa. El primero se comprometió a pintar para el segundo "los cuatro tiempos del año", es decir, las cuatro estaciones, indicándose en el contrato que los pintaría de acuerdo a un "modelo" del pintor Miguel Gómez. ${ }^{8}$ Términos como "bocetos o muestras" son empleados con frecuencia en los contratos del siglo XVI, donde se observa, en los casos que se han conservado, una total relación entre los dibujos y las obras ya terminadas.

En ambos tipos de contratos, a lo largo de todo el siglo XVI, se advierte un innegable sometimiento del artista a la voluntad del cliente, es decir, de quien pagaba.

En mucha ocasiones, los clientes no sólo fijaron la iconografía de la obra, sino también la estructura de las escenas hasta en los más mínimos detalles, esquemas tomados generalmente de estampas u otras obras que servían de referencia.

Este sistema de trabajo fue habitual en todos los artistas sevillanos, incluso en los maestros de primera línea. Sirva como ejemplo el encargo que en 1585 realizó Gerónimo de Aliaga, vecino de Lima, a Juan Bautista Vázquez el Viejo de una imagen de san Gerónimo, en madera de cedro, la cual habría de tener 
la "forma, hechura e postura" de la que se conserva en Sevilla, posiblemente refiriéndose a la obra en terracota policromada del Torrigliano. ${ }^{39}$

Insistiendo en esta idea, en ocasiones, en los contratos se precisaron detalles que hoy día podrían parecer accesorios, como qué figuras deberían llevar diademas o a cuáles se les resaltaría con oro los bordes de las túnicas.

Así actuó Juan de Saucedo, quien, al encomendarle el deán de la catedral de Sevilla la ejecución de un retablo en I592, le indicó que lo pintase reproduciendo con toda fidelidad otro más antiguo existente en ese templo. ${ }^{40}$

Teniendo en cuenta lo expuesto, es fácil comprender que los artistas sevillanos —incluidos entre ellos quienes, según la actual historiografía artística, gozaban de mayor prestigio - aceptaran con toda naturalidad copiar, retocar y rehacer obras de etapas anteriores.

Respecto al primer punto, rara fue la flota de Indias del siglo Xvi que en las bodegas de sus barcos no transportara copias del mural de la "Virgen de la Antigua", en ocasiones, de mano de pintores de primera fila como Alejo Fernández, Esturmio y Campaña. Aunque no se conservan las copias de los dos últimos maestros, el hecho de que la totalidad de las pintadas durante los siglos XVI y XVII la reproduzcan con muy pocas diferencias permite suponer que ellos la copiaron asumiendo circunstancialmente el estilo del anónimo y por entonces arcaizante autor del mural.

Por medio de ejemplos como el expuesto se evidencia el papel determinante que la voluntad de los clientes tuvo en la concreción de las obras. De hecho, éstos podían imponer a los maestros hasta el estilo, especificando en los conciertos que las llevarían a cabo según "el arte que me dixerdes", obligándoles a acatar las reglas del arte (estilo) imperante en cada momento en la ciudad. ${ }^{4 I}$

Dada la naturaleza jurídica de este tipo de conciertos, en los cuales una de las partes se obliga a hacer para la otra una obra determinada, el cliente no

39. Margarita Estella Marcos, Juan Bautista Vázquez el Viejo en Castilla y América, Nicolás de Vergara, su colaborador (Madrid: Consejo Superior de Investigaciones Científicas, 1990).

40. La prueba de que al pintarlo debió renunciar a su estilo se desprende del contenido del contrato, pues al tratar de las figuras de san Isidoro y san Leandro, el deán le señaló expresamente que deberían tener las mismas medidas e idéntico colorido que las del retablo que reproducía, con los "rostros, pies y manos con la misma mitación [sic] que está pintado, porque esto es lo que se pretende" (López Martínez, Desde Martínez Montañés hasta Pedro Roldán, 203).

4I. No obstante, en ocasiones, en especial en lo referente a cuestiones específicamente pictóricas, se permitía que eligiesen entre diversas soluciones: por ejemplo, podían optar por representar a las figuras sentadas o de pie, o ante un fondo de paisaje o en hornacinas. 
sólo podía precisar inicialmente con toda exactitud el objeto de la prestación, sino que asimismo podía seguir de cerca su ejecución para comprobar que ésta se llevaba a cabo de acuerdo con sus directrices.

Al firmar esos contratos se convenía como norma que el pago se efectuaría en plazos, por lo general en tres, coincidiendo con el inicio de la obra, con la mitad y con su conclusión y definitivo asentamiento. Al hacer efectivo el último pago, el cliente vería lo realizado y comprobaría si se atenía o no a lo fijado inicialmente por él. Si era así le pagaría, pero si no, el artista tendría que volver a realizarlo, corriendo de su cuenta los gastos de la repetición.

Por tanto, asegurando los clientes el control de las obras, quiénes las ejecutaran era, la mayoría de las veces, una cuestión secundaria. Esto se manifiesta en los contratos celebrados mediante subasta a la baja. En ellos, los criterios que determinaban la elección de los maestros no venían fijados por las preferencias artísticas de los comitentes, sino por cuestiones puramente económicas, pues como hemos visto líneas arriba, las obras eran encargadas a quienes se comprometían a realizarlas por un precio más bajo.

En general, el sometimiento del artista a la clientela y el desinterés que, como consecuencia de ello, en ciertos casos ésta mostraba por quien ejecutaría la obra justifican la intervención en una misma empresa, sin crear en principio problemas de orden estilístico, de varios maestros de un mismo arte. Éstos podían actuar bien simultánea o bien sucesivamente. De hecho, la mayoría de los grandes retablos sevillanos del siglo Xvi se esculpieron, pintaron e incluso se policromaron por varios maestros a veces al unísono. ${ }^{42}$

Hoy día resulta difícil entender que la tarea de pintar las tablas o los lienzos de un retablo la llevaran a cabo simultáneamente diversos maestros, reticencia motivada, sobre todo, por la creencia de que cada pintor tenía su propio estilo. Sin embargo, esto sólo es verdad en parte, pues, a excepción de determinadas figuras, la mayoría de los maestros se expresaba, aunque con ligeras variantes, de acuerdo con un mismo lenguaje artístico.

42. Así ocurrió, entre otros muchos ejemplos, con el retablo mayor de la parroquia de Santiago de Jerez de la Frontera, cuya policromía encargó el entallador Francisco Ortega a diversos pintores sevillanos, entre otros a Francisco Pacheco, Pablo Legot, Alonso Cano y Francisco Fernández de Llera, quienes se constituyeron en compañía ante la magnitud de la empresa (Enrique Valdivieso y Juan Miguel Serrera, Pintura sevillana del primer tercio del siglo XVII [Madrid: Centro de Estudios Históricos-Departamento de Historia del Arte Diego Velázquez, I985], 43). 
Según lo expuesto, tampoco debe sorprender que una vez contratada una obra, quien se había hecho cargo de ella la traspasara o cediera. Esto se podía efectuar tanto antes de iniciarla - lo que, en principio, puede resultar lógico- como una vez comenzada lo que hoy día es más difícil de entender. Tanto en un caso como en otro, los traspasos podían tener motivaciones muy variadas — enfermedades, fallecimientos, viajes, entre otros - pero fundamentalmente se debían a cuestiones meramente lucrativas: al subarrendar la ejecución de la obra por un precio inferior al contratado, se reservaba el beneficio de la diferencia.

Respecto al tema de los traspasos de obras, el mejor ejemplo es el de Pablo Legot, quien, partiendo del hecho de que era pintor de fábricas del arzobispado sevillano, se hizo cargo de la ejecución de la mayoría de los retablos construidos entonces. De hecho, más que dedicarse a pintar, se ocupó sobre todo de dirigir durante largos ańos un próspero negocio de traspaso casi sistemático de los encargos que asumía, si bien por un precio mucho más bajo, y a formar compañías con otros maestros. ${ }^{43}$

Esos traspasos, así como las cesiones, se hacían por lo general con el consentimiento de los clientes, a quienes no les importaba tanto quién ejecutara las obras, sino que se realizaran siguiendo sus órdenes, prioridad de intereses manifestada en los mismos conciertos, pues una de las cláusulas introducidas por los clientes se refería a que si un maestro no entregaba una obra en el plazo prefijado podían encargársela a otro artista, quien la ejecutaría a costa del primero. En otros casos se especificaba que si una vez entregado el primer lienzo no gustaba al comitente, éste podía rescindir el contrato y encargar la obra a otro maestro.

A modo de resumen podemos afirmar que el descubrimiento de América y la posterior consolidación de la sociedad colonial trajeron consigo una renovación completa de la organización del trabajo y de los sistemas de producción en los talleres artísticos sevillanos, los cuales, a lo largo del siglo xvi, abandonaron los viejos sistemas de raigambre medieval y los sustituyeron por otros de rasgos claramente modernos. के

43. La gestión de esos negocios le exigió fuertes inversiones para adquirir materiales y pagar a los maestros que trabajaban para él, lo cual lo obligó en varias ocasiones a pedir dinero prestado, llegando incluso a hipotecar su casa (Valdivieso y Serrera, Pintura sevillana, 26r). 